\title{
Características Fenológicas de Baccharis trimera (Less.) DC. (1836) - Asteraceae - no município de Viçosa, Minas Gerais, Brasil
}

SOUSA, L.A. ${ }^{1 *}$; VENZKE, T.S. ${ }^{2}$; MARTINS, S.V. ${ }^{3}$; FREITAS, G.B. ${ }^{4}$

${ }^{1}$ Doutorando do Programa de Pós-Graduação em Fitotecnia Universidade Federal de Viçosa, UFV, Avenida Peter Henry Rolfs, s/n, Campus Universitário, Viçosa, MG, CEP 36570-000; ${ }^{2}$ Mestrando do Programa de PósGraduação em Botânica, UFV; ${ }^{3}$ Professor Doutor do Departamento de Engenharia Florestal, UFV; ${ }^{4}$ Professor Doutor do Departamento de Fitotecnia, UFV. *leonardo.a@ufv.br

RESUMO: Quatro populações de Baccharis trimera (Asteraceae) foram analisadas no município de Viçosa-MG quanto ao ciclo fenológico. As observações foram realizadas mensalmente de março de 2010 a março de 2011 acompanhando a fenofase vegetativa e reprodutiva em espécimes ocorrentes em diferentes ambientes - barranco, mata de eucaliptos, mata secundária e pastagem. Os indivíduos do barranco e da pastagem floresceram durante maio, junho e julho e frutificaram entre agosto e setembro. As plantas em sub-bosque de mata secundária não apresentaram a fenofase reprodutiva. A floração e a frutificação das plantas na mata de eucalipto ocorreram após um mês em relação às outras populações. O conhecimento preliminar do ciclo fenológico da espécie contribui para a estratégia de seu manejo sustentável e emprego medicinal.

Palavras-chave: Baccharis trimera, ciclo fenológico, planta medicinal, Viçosa.

ABSTRACT: Phenology of populations of "carqueja" [Baccharis trimera (Less.) DC. - Asteraceae] in the municipal district of Viçosa, Minas Gerais, Brazil.Fourpopulations ofBaccharistrimera (Asteraceae) were analyzedin Viçosa-MG in relation to thephenological cycle. The observations weretaken monthly fromMarch 2010to March 2011following thevegetativeand reproductivephenologyinspecimensoccurringin differentenvironmentsravine,forestof eucalyptus trees, secondary forest and pasture. Individualsfrom the ravineand pasturebloomed duringMay, June andJuly andbore fruitin August and September. The plantsof thesecondary forestunderstoryshowed noreproductivephenology. Flowering andfruiting ofplantsin the forestofeucalyptustrees occurredafter one monthcompared toother populations. Preliminary knowledgeof the phenological cycleof the speciescontributes toits sustainable managementstrategyandmedicinaluses.

Keywords: Baccharis trimera, ciclo fenológico, planta medicinal, Viçosa.

\section{INTRODUÇÃO}

A fenologia é definida como um conjunto de caracteres de cada uma das etapas que ocorrem com os vegetais durante o seu ciclo de desenvolvimento (Font Quer, 1953). Os estudos de botânica estão diretamente ligados aos fatores ambientais que em geral determinam os fenômenos biológicos da flora (Borgignon \& Picolo, 1982).

A espécie Baccharis trimera (Asteraceae) é uma planta com propriedades medicinais e aromáticas (Vieira \& Silva, 2002) de ampla distribuição nacional, ocorrendo nos biomas de Cerrado (Rodrigues \& Carvalho, 2001), Mata Atlântica (Pavan-Fruehauf, 2000, Vieira \& Silva, 2002) e Pampa (Ritter \& Baptista, 2005; Caporal \&
Boldrini, 2007). Habita ambientes ruderais (Brandão \& Oliveira 1995; Macedo, 1995; Vieira \& Silva, 2002) e ainda é considerada uma espécie bioindicadora de solos compactados (Burg \& Mayer, 2002).

Estudos das fenofases são importantes para fornecer subsídios no manejo da espécie, pois conforme Vieira \& Silva (2002), a espécie carece de informações da biologia floral e sistema reprodutivo. A fenologia no caso de plantas medicinais determina a época adequada para a coleta das sementes e de material vegetativo, evitando prejudicar a capacidade da reprodução e manutenção das populações no ambiente. Assim este estudo teve como objetivo fornecer informações básicas dos 
ritmos fenológicos de quatro populações de $B$. trimera em diferentes ambientes no município de Viçosa, Minas Gerais, Brasil.

\section{MATERIAL E MÉTODOS}

O município de Viçosa está localizado na influência da Floresta Estacional Semidecidual, na latitude de $20^{\circ} 45^{\prime} 25,2^{\prime \prime}$ e longitude de $42^{\circ} 52^{\prime} 09,5^{\prime \prime}$. As altitudes variam de 600 a $800 \mathrm{~m}$ (Pinheiro et al., 1992). O clima na região é tipo Cwb conforme classificação do sistema de Koppen, mesotérmico com verões quentes e chuvosos e invernos secos e frios. A temperatura média anual é de $19^{\circ} \mathrm{C}$ e a precipitação média é de 1.341,2 mm (Castro et al., 1983).

A identificação de Baccharis trimera (Less.) DC. (1836) - Asteraceae - foi realizada com uso de chave de identificação (Barroso, 1976) e auxílio de lupa de bolso (aumento 3x). O material botânico de referência foi coletado e submetido à confecção de exsicatas, sendo posteriormente incorporado ao acervo do Herbário do Departamento de Biologia Vegetal/UFV (VIC 33.093).

As populações de $B$. trimera monitoradas de forma sistemática [mínimo de indivíduos encontrados] e de forma aleatória, Ad libitum (Altmann, 1974), [vistos em qualquer espaço do transecto de amostragem: antrópico, ruderal ou ambiente florestal sombreado ou não] estão relacionadas na tabela 1 e distribuídas em diferentes ambientes no município de Viçosa. Na determinação da localização das populações foi utilizado um GPS de navegação (etrex-Legend/GARMIN).

As fenofases observadas foram: vegetativa (presença somente de folhas), botões (presença de botões florais), floração (presença de botões florais e/ou flores) e frutificação (botões florais, presença de flores, frutos imaturos e maduros). As observações foram realizadas mensalmente durante um ano (março de 2010 a março de 2011) e o diagrama climático da precipitação e da temperatura, figura
1, foi construído com os dados climáticos de 1970 á 2010 do Instituto Nacional de Meteorologia (INMET).

\section{RESULTADOS}

As fenofases: vegetativa, botões florais, floração e frutificação, ocorreram sucessivamente em B. trimera, Tabela 2, exceto para plantas do interior de floresta secundária (Dendrologia), as quais foram às únicas que não se reproduziram no período analisado, permanecendo somente na fase vegetativa.

A maioria das populações teve sincronia próxima entre floração e o período de menor precipitação e temperatura. Este período ocorreu durante os meses de junho, julho, agosto (Figura 1).

Observou-se que as plantas permanecem cerca de três a cinco meses com botões florais, variando o tempo conforme as condições fenomenológicas locais, bem como a floração (dois a três meses) e frutificação (um a três meses). Durante os meses de novembro, dezembro, janeiro e fevereiro somente observou-se a fase vegetativa, indicando ser, provavelmente, a época de crescimento vegetativo da planta para esta microrregião da Zona da Mata Mineira.

Os indivíduos do barranco e da pastagem florescem durante junho, julho e agosto e frutificando durante agosto e setembro. Em relação às estas populações, as plantas da mata de eucalipto atrasaram um mês para os eventos de floração e frutificação. Os frutos foram observados apenas no mês de setembro nas plantas da mata de eucalipto.

\section{DISCUSSÃO}

A floração da espécie $B$. trimera durante o período de menor precipitação foi também observado por Macedo (1995) estudando plantas invasoras no Campus-Pampulha da Universidade Federal de Minas Gerais. Os autores encontraram $B$. trimera em floração durante os meses de junho e julho, meses no qual ocorreu menos de $10 \mathrm{~mm}$ de

TABELA 1. Dados populacionais de Baccharis trimera em Viçosa-MG, Brasil

\begin{tabular}{|c|c|c|c|c|}
\hline Populações & Altitude & $\begin{array}{l}\text { Coordenadas } \\
\text { geográficas }\end{array}$ & $\begin{array}{c}\text { Numero } \\
\text { de indivíduos }\end{array}$ & $\begin{array}{c}\text { Características do } \\
\text { ambiente }\end{array}$ \\
\hline \multirow{2}{*}{ Bovinocultura } & \multirow{2}{*}{$675 \mathrm{~m}$} & S2046’25,4"' & \multirow{2}{*}{$10\left(5 \circ / 5{ }^{\Uparrow}\right)$} & Barranco com \\
\hline & & WO4251'42,6”' & & gramíneas e Brachiaria. \\
\hline \multirow{2}{*}{ Cachoeirinha } & \multirow{2}{*}{$734 \mathrm{~m}$} & $\mathrm{~S} 20^{\circ} 44^{\prime} 37,7^{\cdots}$ & \multirow{2}{*}{$10\left(6+/ 4 \delta^{\lambda}\right)$} & \multirow{2}{*}{ Pastagem } \\
\hline & & WO $42^{\circ} 46^{\prime} 22,3^{\prime \prime}$ & & \\
\hline \multirow{2}{*}{ Mata de Eucalyptus } & \multirow{2}{*}{$729 \mathrm{~m}$} & S2043'38,4" & \multirow{2}{*}{$20(10 \bigcirc / 10 \precsim)$} & Lavoura abandonada de \\
\hline & & WO4246’10,4”' & & Eucalyptus sp. com Brachiaria \\
\hline \multirow{2}{*}{ Dendrologia } & \multirow{2}{*}{$698 \mathrm{~m}$} & S2046’35,1"' & \multirow{2}{*}{5 (indet.) } & \multirow{2}{*}{ Floresta secundária } \\
\hline & & WO42 $52 ' 21,7^{\prime \prime}$ & & \\
\hline
\end{tabular}

Rev. Bras. PI. Med., Campinas, v.16, n.1, p.112-116, 2014. 


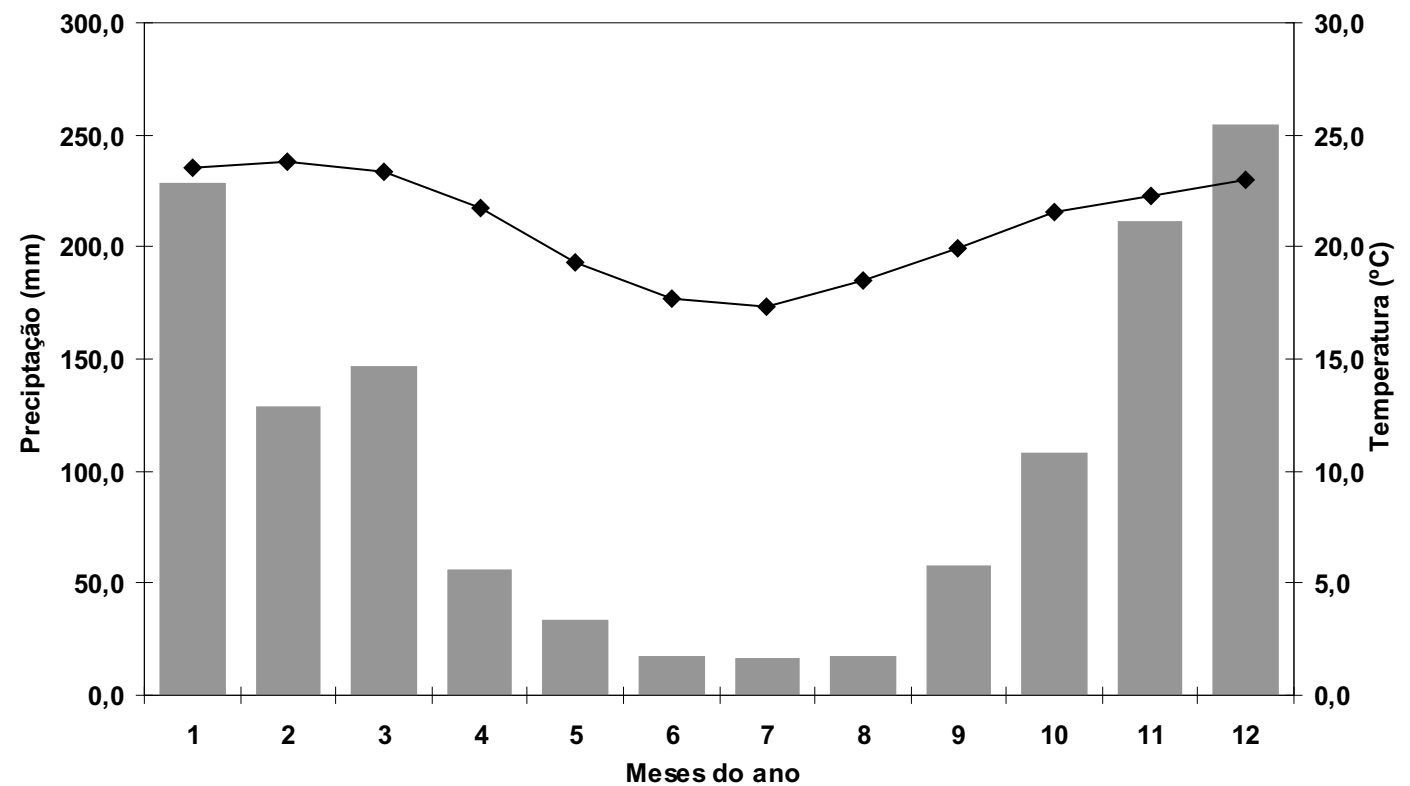

FIGURA 1. Diagrama climático (média de precipitação e temperatura) para o Município de Viçosa, MG, Brasil (normal climatológica de 1970-2010 - Instituto Nacional de Meteorologia-INMET)

TABELA 2. Ritmo fenológico de populações de Baccharis trimera de quatro locais no Município de Viçosa, MG, Brasil

\begin{tabular}{|c|c|c|c|c|c|c|c|c|c|c|c|c|c|}
\hline \multirow[b]{2}{*}{ Populações } & \multicolumn{10}{|c|}{2010} & \multicolumn{3}{|c|}{2011} \\
\hline & mar & abr & mai & jun & Jul & ago & Set & out & Nov & dez & Jan & fev & Mar \\
\hline Bovinocultura & $\bullet$ & 甲 & 甲 & $\circ \nabla$ & 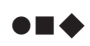 & $\bullet \bullet \star$ & • & • & - & - & • & - & 甲 \\
\hline $\begin{array}{l}\text { Cachoeirinha } \\
\text { Mata de }\end{array}$ & $\bullet$ & $\bullet$ & $\bullet$ & $\bullet \bullet$ & 마 & $\bullet \bullet \diamond \star$ & • & $\bullet$ & $\bullet$ & $\bullet$ & • & $\bullet$ & • \\
\hline $\begin{array}{l}\text { eucaliptos } \\
\text { Dendrologia }\end{array}$ & $\bullet$ & $\bullet$ & $\bullet$ & $\bullet$ & $\bullet$ & $\bullet \bullet$ & • $\star$ & $\bullet$ & $\bullet$ & $\bullet$ & $\bullet$ & $\bullet$ & $\bullet$ \\
\hline
\end{tabular}

Legenda: $\bullet$ vegetando; $\boldsymbol{\square}$ botões; $\bullet$ floração; $\star$ frutificação

precipitação na região deste estudo. Isso evidencia a relação da fenofase reprodutiva $B$. trimera com a época seca. O autor salienta que durante a época da estiagem, a presença de plantas com floração, representa uma fonte de recurso para os insetos que dependem de flores para a sua sobrevivência, melhorando o planejamento de sistemas de manejo das propriedades rurais, corroborando com Pirani e Laurino (1994) que já demonstraram o potencial apícola para este recurso vegetal em áreas antrópicas.

A espécie apresenta sincronismo variado entre a fenofase reprodutiva (floração e frutificação) com os ritmos climáticos, equivalentes aos meses frios e secos, indicando uma estratégia de estabelecimento da próxima geração no ambiente. A frutificação das populações da espécie foi mais frequente durante os meses de agosto e setembro. Em agosto o clima seco contribui para a dispersão dos frutos anemocóricos da espécie. Frutos anemocóricos possuem adaptações morfológicas para a dispersão através do vento (Van der Pijl, 1969) como, exemplo, as estruturas voadoras dos frutos de $B$. trimera que provem do cálice modificado da flor em forma de apêndices plumados. Deste modo o ambiente seco promove melhor potencialidade no processo da dispersão dos propágulos da espécie no ambiente. Assim, após a dispersão, nos meses de setembro e outubro, com o começo das chuvas, a umidade determina a maior possibilidade da germinação e estabelecimento dos novos indivíduos no ambiente.

A permanência em fase vegetativa da população localizada no interior da floresta secundária - vegetando no sub-bosque - ocorre devido à espécie ser heliófita (Reis, 1996). Assim é notória a necessidade de luminosidade mais intensa - exposta a pleno sol - para expressar a fenofase de floração e de frutificação. Destaca-se também 
uma redução de espécimes neste ambiente, mas conforme os resultados encontrados para espécies ocorrentes em Matas de eucaliptos (árvores que apresentam um dossel menos denso, favorecendo a maior penetração de raios solares) pode haver apenas uma alteração no ritmo fenológico e assim promover uma floração em épocas diferenciadas daquelas observadas para populações que habitavam áreas expostas a incidência plena de luminosidade (Tabela 2).

De acordo com o conhecimento do ciclo fenológico de $B$. trimera para o município de Viçosa, ainda é possível indicar seu manejo para controle populacional em pastagens e produção de matéria prima, a partir da roçada durante o período da primavera e verão (estações quente e úmida). Pois, conforme Scheffer-Basso et al. (2008) em estudo morfofisiológico da rebrota de carqueja para o controle da espécie em pastagens naturais, verificaram menor capacidade de rebrota quando a roçada é realizada no começo da primavera, independente da altura (7 ou $15 \mathrm{~cm}$ ). Já quando realizada no começo do outono o corte deve ser mais baixo $(7 \mathrm{~cm})$. Ambos os tratamentos de altura foram mais eficazes no controle da carqueja quando realizado no estágio vegetativo. Porém, são escassas as investigações sobre o manejo da biomassa de $B$. trimera, além de que são necessários estudos de alta prioridade com sistema reprodutivo conforme relatado por Vieira e Silva (2002) se tratando de B. trimera ocorrente no bioma Mata Atlântica ou cultivada, invasora e ruderal; e outras abordagens em biologia floral que possam contribuir para o melhor entendimento do ciclo vital da espécie, bem como fornecer subsídios para o melhoramento vegetal.

O conhecimento dos ritmos fenológicos demonstrou que para as condições climáticas de Viçosa a melhor época para a coleta das sementes são agosto e setembro, apesar de que ainda não existe literatura específica que assegure as melhores condições de propagação reprodutiva, quando os frutos estão em processo de amadurecimento na maioria das populações estudadas. Também é notório que o conhecimento do ciclo fenológico da espécie contribua para seu manejo sustentável e emprego medicinal, apesar de ser necessário o entendimento da sazonalidade química da espécie e seus possíveis ecótipos para um emprego fitoterápico eficiente.

Portanto, as informações fenológicas obtidas neste trabalho evidenciaram a existência de sazonalidade fenológica, uma vez que a espécie apresenta uma ampla distribuição geográfica pelo território nacional, o que reforça a necessidade de outros trabalhos envolvendo a variabilidade das fenofases para espécie e sua relação com a qualidade fitoterápica.

\section{CONCLUSÕES}

Para Baccharis trimera a fase de floração coincidiu com o período seco. A frutificação da maioria das populações apresentou sincronia e coincidiram com o final do período seco e começo do chuvoso.

As fenofases indicam, de forma preliminar, que a espécie está adaptada para aproveitar o período seco no processo da dispersão das sementes anemocóricas e no período úmido para a germinação, estabelecimento e crescimento das plântulas em ambientes naturais.

\section{REFERENCIA}

ALTMANN, J. Observational stdy of behaviour: sampling methods. Behaviour, v.49, p.227-267, 1974.

BARROSO, G.M. Compositae - Tribo Baccharidinae Hoffmann: estudo de espécies ocorrentes no Brasil. Rodriguesia, v.40, n.3, p.1-273, 1976.

BORGIGNON, O.J.; PICOLO, A.L.G. Fenologia de Hydiocotyle leucocephala Cham. Rodriguesia, v.34, n.56, p.91-100, 1982.

BRANDÃO, M.; OLIVEIRA, A.K. Plantas ruderais e subespontâneas do Município de Ouro Preto e sua utilização na Medicina Popular. Daphne, Belo Horizonte, v.5, n.2, p.49-71, 1995.

BURG, C.I.; MAYER, H.P. Alternativas ecológicas para prevenção e controle de pragas e doenças. 17.ed. Francisco Beltrão: Editora Grafit, 2002.153p.

CAPORAL, F.J.M.; BOLDRINI, I.I. Florística e fitossociologia de um campo manejado na Serra do Sudeste, Rio Grande do Sul. Revista Brasileira de Biociências, v.5, n.2-3, p.37-44, 2007.

CASTRO, P.S.; VALENTE, O.F.; COELHO, D.T.; RAMALHO, R.S. Interceptação da chuva por mata natural secundária na região de Viçosa, MG. Revista Árvore, v.7, n.1, p.76-89, 1983.

FONT QUER, P. Diccionario de Botánica. Barcelona: Editorial Labor, 1953. 1244p.

MACEDO, J.F. Fenologia da floração das plantas Invasoras no Campus-Pampulha da Universidade Federal de Minas Gerais. Daphne, v.5, n.4, p.15-27, 1995.

PAVAN-FRUEHAUF, S. Plantas Medicinais de Mata Atlântica: manejo sustentado e amostragem. São Paulo: Annablume/Fapesp. 2000. 216p.

PINHEIRO, A.L.; RODRIGUES, J.P.F.; MARANGON, L.C. Características fenológicas do Urucum (Bixa orellana L. var. "fruto vermelho piloso" em Viçosa, Minas Gerais. Daphne, v.2, n.3, p.7-10, 1992.

PIRANI, J.R.; LAURINO, M.C. Flores e Abelhas em São Paulo. São Paulo: Editora da USP. 1994. 192p.

REIS, M.S. Manejo Sustentado de Plantas Medicinais em Ecossistemas Tropicais. In: DI STASI, L.C. (org.) Plantas Medicinais: Arte e Ciência - Um guia de estudo 
interdisplinar. São Paulo: Editora da Universidade Estadual Paulista, 1996, p.199-215.

RITTER, M.R.; BAPTISTA, L.R.M. Levantamento florístico da família Asteraceae na "Casa de Pedra" e áreas adjacentes, Bagé, Rio Grande do Sul. Iheringia: Série Botânica, v.60, n.1, p.5-10, 2005.

RODRIGUES, V.E.G.; CARVALHO, D.A. Plantas Medicinais no Domínio do Cerrados. Lavras: Editora da UFLA, 2001. 180p.

SCHEFFER-BASSO, S.M.; LUDENOW, R.; CARNEIRO, C.M.; CHINI, S.O. Morfofisiologia da rebrota de Baccharis trimera (Less) DC., Asteraceae: Subsídios para o seu controle em pastagens naturais. Revista
Biotemas, v.21, n.3, p.31-37, 2008.

SOUSA, L.A.; SACRAMENTO, L.V.S.; MING, L.C. Propagação por estaquia de três acessos de Baccharis trimera em fenofase reprodutiva. Revista Brasileira de Plantas Medicinais, v.8, n.4, p.189-192, 2006.

VIEIRA, R.F.; SILVA, S.R. In: Estratégias para Conservação e Manejo de Recursos Genéticos de Plantas Medicinais e Aromáticas. In: RESULTADOS DA $1^{\circ}$ REUNIÃO TÉCNICA, Brasília: Embrapa/lbama/MMA/CNPq, 2002. $184 p$.

VAN DER PIJL, L. Principles of Dispersal in Higher Plants. Berlin-NewYork: Ed. Springer-Verlag, 1969. $154 p$. 